\title{
The Linkage Between Solar Insolation and Dust in the Major World Deserts
}

\author{
J. Barkan* and P. Alpert
} Department of Geophysics and Planetary Sciences, Raymond and Beverly Sackler Faculty of Exact Sciences, Tel-Aviv
University, Tel-Aviv, Israel

\begin{abstract}
The annual link between the solar insolation, the surface temperature, and the dust load in the atmosphere as estimated by the TOMS Aerosol Index was compared in five major sandy deserts around the globe.

A high correlation was found between the insolation and the dust in all deserts, while the correlation of dust with temperature was lower. The peaks of the insolation and the dust occurred almost simultaneously on the same date in three out of the five deserts i.e. Sahara, S.W. North American, Atacama. In the other two deserts i.e., Australian, Taklimakan, the peak of the dust occurs earlier in the year. The temperature peaks occur on a later date in all the deserts. Our conclusion is, that in the deserts of the world the radiation is the major cause of the total dust loading.
\end{abstract}

Keywords: Insolation, desert, dust, temperature, TOMS.

\section{INTRODUCTION}

Alpert et al. 2006 [1] found that the total amount of dust in the atmosphere is highly correlated with the solar insolation over the Saharan desert. Moreover, the annual maximum is reached almost on the same day, while the maximum temperature occurs a month later. This high match exists in the very great expanse of the Sahara, while in smaller areas (like the three distinct parts of the Sahara that were examined), other variables, like the local topography, the synoptic situation, etc., appear to weaken the link between dust and insolation, thus lowering the correlation. The theoretical foundation for this high correlation was discussed in detail in that paper and are summarized in chapter 2 of this paper.

In this manuscript, we compare the annual link between dust, solar insolation, and the surface temperature in the Sahara and four other major sandy deserts in the world. The four other deserts examined are: the sandy part of the Australian desert, the Arizona and Sonora deserts in the Southwestern U.S and Mexico, the Taklimakan Desert in China, and the Atacama Desert in Chile. We show that in all these deserts the role of solar insolation concerning dust loading is very important, even dominant. This, in spite of the smaller areas of these deserts when compared with the Sahara, as well as their less favorable environment, such as more rugged topography, and stronger and more erratic synoptic systems.

One potential application of the present findings may be the direct incorporation of the solar insolation in dust prediction models. The strong correlation of radiation and dust load dates in the major deserts around the world can further improve these models. Better models for short and long term forecasting of dust events can aid in dealing with

*Address correspondence to this author at the Department of Geophysics and Planetary Sciences, Raymond and Beverly Sackler Faculty of Exact Sciences, Tel-Aviv University, Tel-Aviv, Israel; Tel: 97236405694; Fax: 97236409282; E-mail: yossibenator@gmail.com several very important topics, like air pollution, public health, land and air traffic, house management, etc.

\section{THEORY}

The local generation of mineral dust is directly related to the uplifting dust processes that were studied quite extensively e.g. Bagnold 1965 [2], Balkanski 1996 [3]. The main variables influencig this process are the solar insolation i.e. the downwelling solar flux, the wind intensity and the atmospheric stability. The amount of vegetation and the soil moisture also influence the uplift somewhat. However, the solar heating is implicitly responsible for the process of both dust uplifting and of the maintaining of the high amount of the dust in the atmosphere. Solar daily heating of the land surface is the major forcing for buoyant production of turbulent kinetic energy (TKE) on days of free convection (Stull 1988) [4]. The second important term in the generation of TKE is the mechanical shear production, which is proportional to the square of the vertical wind shear $(\partial \overline{\mathbf{u}} / \partial z)$. In other words: the solar insolation and the wind velocity are the main variables responsible for the uplifting of dust and maintaining it in the atmosphere.

\section{METHODOLOGY}

The satellite mounted Total Ozone Mapping Spectrometer (TOMS) daily data were used to estimate an index called Aerosol Index (AI) for the total dust amount over a given area with a spatial resolution of $1.25^{\circ}$ longitude and $1^{\circ}$ latitude (Herman and Celarier, 1997) [5]. This index utilizes the spectral contrast of two ultraviolet channels: 340 $\mathrm{nm}$ and $380 \mathrm{~nm}$. It provides an estimate for the integral amount of the aerosol in the column along the line of sight and it is positive for dust.

Since the albedo in the UV is very low, this method is able to provide a dust measure everywhere above land or sea, and is unique among the dust measuring instruments that cannot gather data above high albedo surfaces like deserts (Prospero et al., 2002) [6]. 
For the daily surface radiation and temperature, the NCEP/NCAR reanalysis was employed (Kalnay et al., 1996) [7], with units of $\mathrm{W} / \mathrm{m}^{2}$, and ${ }^{\circ} \mathrm{C}$, respectively. We are aware that the reanalysis data is model dependent and it has to taken into account. Additionally we have to note that in the reanalysis the radiation balance does not consider daily dust variability. Hence, the extinction within the dust would result in less solar radiation at the surface.

This work is based on 14 years of daily data between the years 1979-1992. For both variables (AI and radiation), the average of the 14 data points for every day was computed, i.e. daily averages of 365 times 14 - 5110 values for each variable.

To determine the annual changes, the peak value and date of the AI and the radiation of every individual year was identified and presented.

\section{THE DESERTS}

The deserts of the world are usually classified by their location relative to the topography, distance from the nearest great water surface, and the average latitude they occupy. There are subtropical deserts, continental deserts, rain shadow deserts, and coastal deserts, part of them warm and part cold (Deserts in Australia, 2006) [8]. Since we were interested in the relation between the solar radiation and the dust, we chose deserts that contain dust and/or aerosols like dust (e.g. fine grained mineral deposits).

Not the whole area of the deserts we considered is always dusty. We tried to identify the dusty parts by averaging the AI data for the 14 years mentioned above for every desert, and pinpointing the dustiest parts according to the method used by Barkan et al. (2004) [9] in the Sahara. Additionally, we were aided by numerous studies on global sources of atmospheric dust and dust storms (Prospero et al. 2002 [6], Washington et al. 2003 [10], Barkan et al. 2004 [9]). Accordingly, the borders of the deserts were defined (Table 1). Consequently, our definition differs somewhat from the various definitions appearing in the literature.

Among the deserts included, the Sahara and the Taklimakan contain great amounts of sand (Huang et al. 2009 [11], Mason et al. 2009 [12]) The Australian desert, although partly covered by rocks and gravel, the part we identified is mostly sandy, and constitutes the sand dunes that extend across in the greatest number of latitudes in the world.

The deserts of the Southwestern U.S. and northern Mexico, although not rich in sand (there is sand mainly in the Great Basin of Utah), contain ample amounts of fine grained mineral deposits which in the air behave like dust. The Atacama desert, although it contains mainly salt deposits, has sand also. Tourists and local researchers report occasional severe dust storms.

We did not include the Gobi desert in this work, although it is one of the largest deserts in the world, since its surface is mainly rocky. Instead, we have chosen the adjacent Taklimakan desert that has very large sand deposits.

The Kalahari desert of Southern Africa was not included as well. It is a sandy desert, but because of the seasonal, very intensive, biomass burning it was impossible to get relevant results for our research (Sinha et al., 2003) [13].

\section{RESULTS AND DISCUSSION}

\section{a. The Average Results}

Fig. (1) shows the annual courses of the solar insolation and the dust in the air, as expressed by TOMS. Fig. (1a) shows the link in the Sahara as defined by Alpert et al., (2006) [1], and is used as the basis for comparison with the other deserts. One can see that the highest dust load in the year occurs almost at the same date as the peak of the solar insolation. The difference is only four days, i.e. 17 and 21 of June, respectively. The change of the two variables along the year is so close that the correlation coefficient is 0.98 (Table 2).

In the Australian desert, the dust peaks considerably before that of the radiation (Fig. 1b) - by 38 days. In spite of this, the correlation coefficient (r) is high -0.75 , meaning that the variability within the year is similar for both variables (Table 2). The behavior of the variables in the Southwestern and Mexican desert (Fig. 1c) is almost identical to that of the Sahara. The difference between the dust and radiation peaks is only three days, and the correlation coefficient (r) is 0.96 (Table 2). In the Taklimakan desert (Fig. 1d), the dust peaks considerably earlier than the radiation peak - by 27 days. Surprisingly, although the dust peaks much earlier, the annual behavior of the variables is very close. The correlation coefficient (r) is 0.92 (Table 2). In the Atacama desert (Fig. 1e), although the dust load value is very erratic throughout the year, the peaks are very close - only three days difference. Because of the erratic behavior of the dust load, the correlation coefficient is lower than for the other deserts, only 0.66 (Table 2).

Note that for all the deserts, except the Atacama, the rate of change of radiation and dust in the first half of the year is almost identical, but not so in the second half. A possible

Table 1. The Geographical Location of the Major Sandy Deserts of the World. Rows from Left to Right: Name, Area $\left(\mathrm{km}^{*} 10^{3}\right)$, Long/Lat Borders (as Defined in Text), and Average Latitude/Longitude

\begin{tabular}{|c|c|c|c|c|}
\hline Desert & Area $\left(\mathbf{k m}^{2} * \mathbf{1 0}^{\mathbf{3}}\right)$ & Borders & Average Latitude & Average Longitude \\
\hline \hline Sahara & 11161 & $15 \mathrm{~W}-60 \mathrm{E}, 15 \mathrm{~N}-35 \mathrm{~N}$ & $25 \mathrm{~N}$ & $22 \mathrm{E}$ \\
\hline Australia & 2275 & $133 \mathrm{E}-144 \mathrm{E}, 31 \mathrm{~S}-13 \mathrm{~S}$ & $22 \mathrm{~S}$ & $138 \mathrm{E}$ \\
\hline S.W. USA & 1520 & $115 \mathrm{~W}-100 \mathrm{~W}, 30 \mathrm{~N}-40 \mathrm{~N}$ & $35 \mathrm{~N}$ & $107 \mathrm{~W}$ \\
\hline Taklimakan & 236 & $80 \mathrm{E}-87 \mathrm{E}, 38 \mathrm{~N}-41.5 \mathrm{~N}$ & $40 \mathrm{~N}$ & $83 \mathrm{E}$ \\
\hline Atacama & 181 & $71 \mathrm{~W}-69 \mathrm{~W}, 27 \mathrm{~S}-18 \mathrm{~S}$ & $22 \mathrm{~S}$ & $70 \mathrm{~W}$ \\
\hline
\end{tabular}


(a)

Mean Annual Aerosol Index vs. Surface Radiation, 1979-1992.

Sahara Desert: Longitude 15W-60E, Latituede 20N-35N.

\section{Cerrelation Coefficient 0.98}

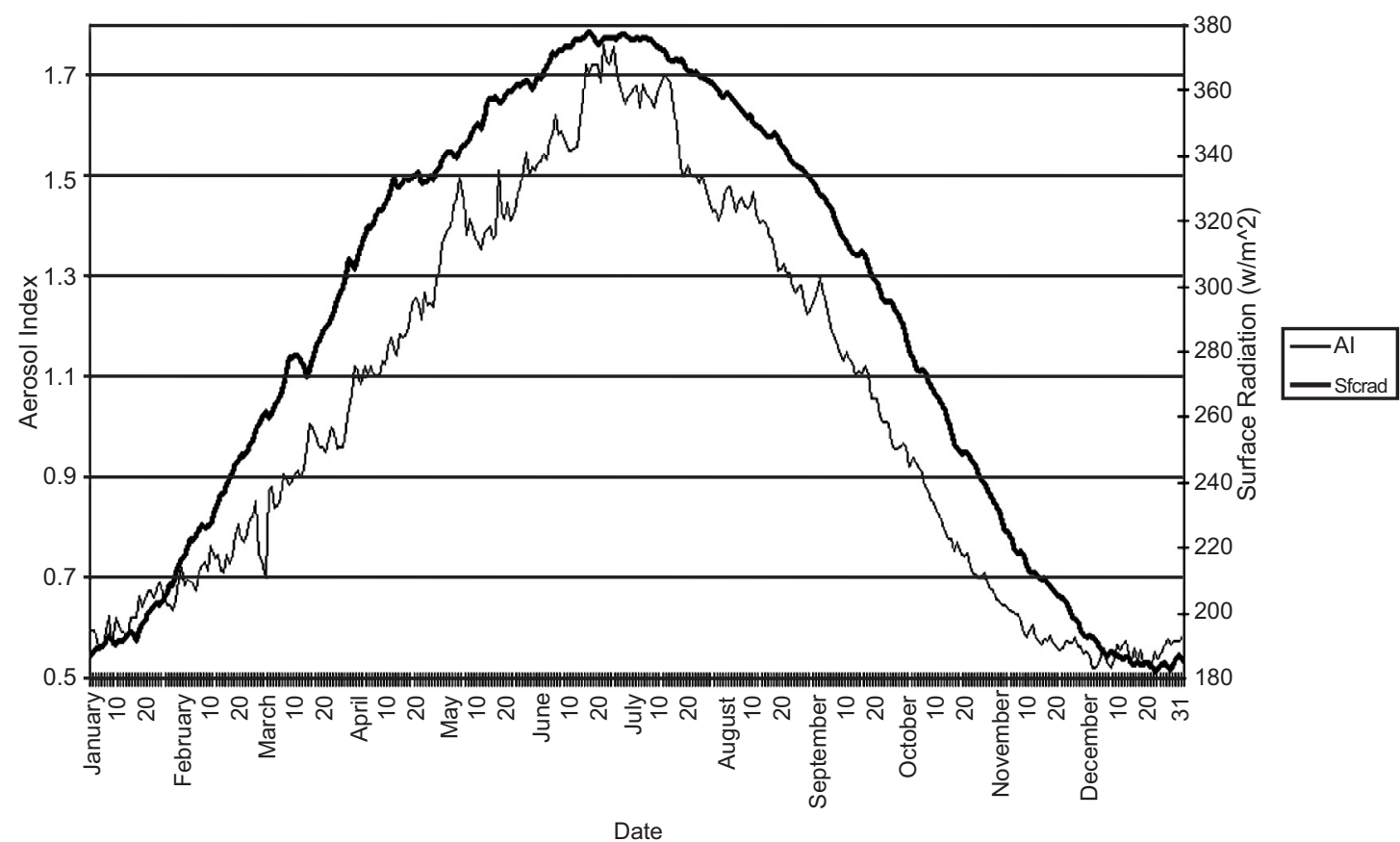

(b)

Mean Annual Aerosol Index vs. Surface Radiation, 1979-1992.

Australian Desert: Longitude 133E-144E, Latituede 31S-13S.

Running Aerage 10 day. Cerrelation Coefficient 0.93.

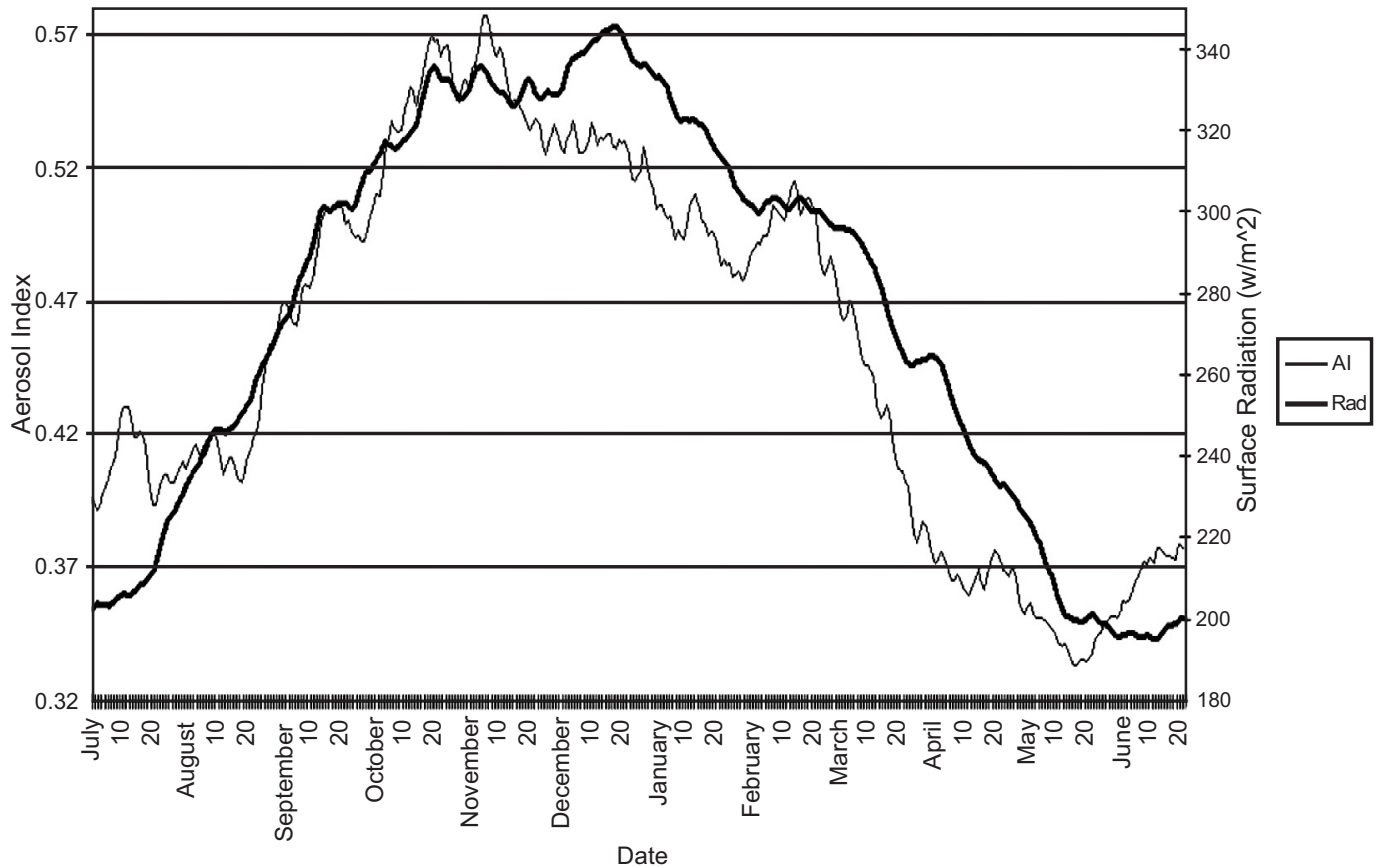


(Fig. 1) contd.....

(c)

Mean Annual Aerosol Index vs. Surface Radiation, 1979-1992.

US Southwestern Desert: Longitude 115W-100W, Latitude 30N-40N.

Running Aerage 10 day. Cerrelation Coefficient 0.96.

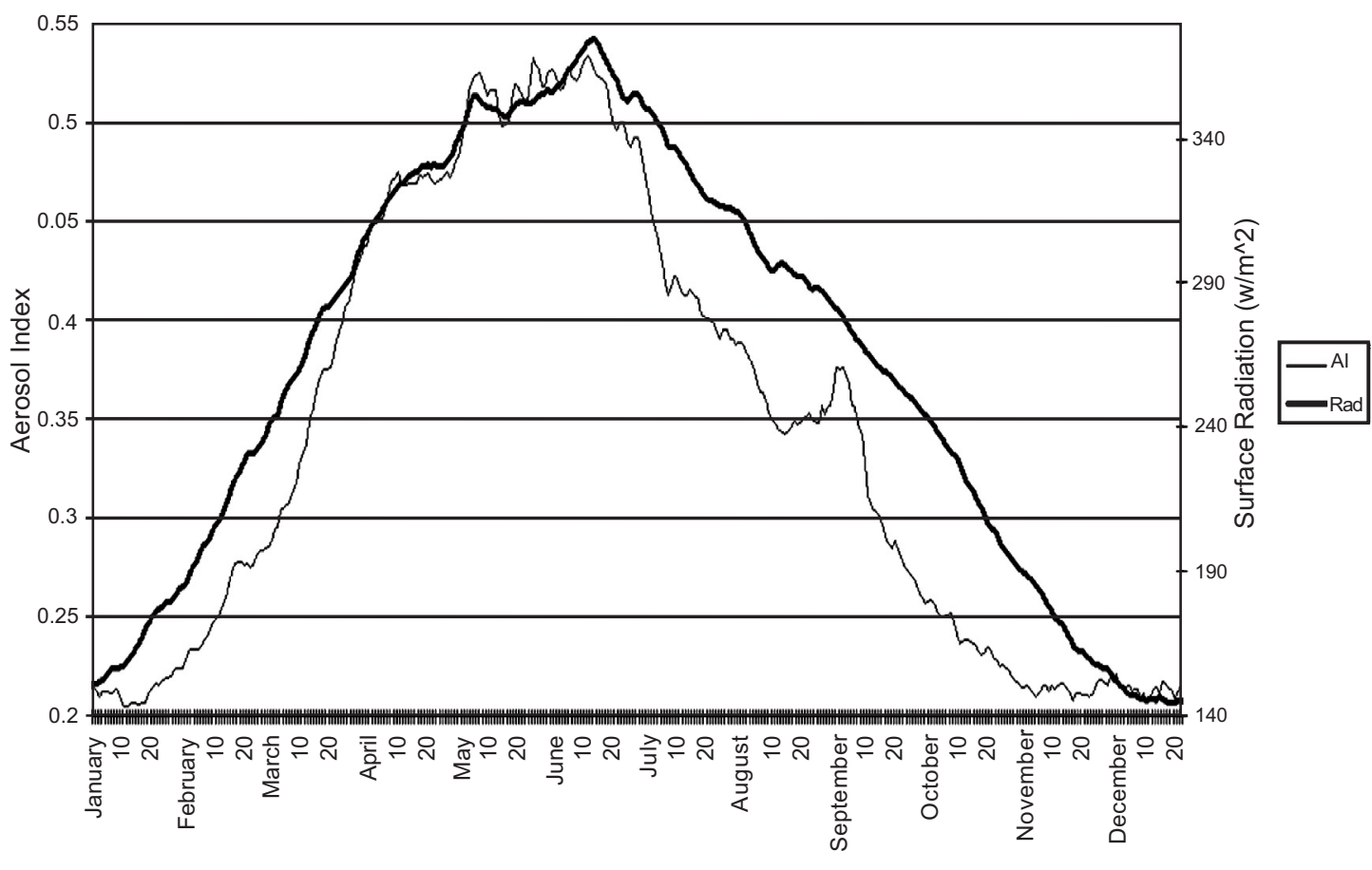

Date

(d)

Mean Annual Aerosol Index vs. Surface Radiation, 1979-1992.

Taklimakan Desert: Longitude 80E-87E, Latitude 38N-41.5N

Running Aerage 10 day. Cerrelation Coefficient 0.92 .

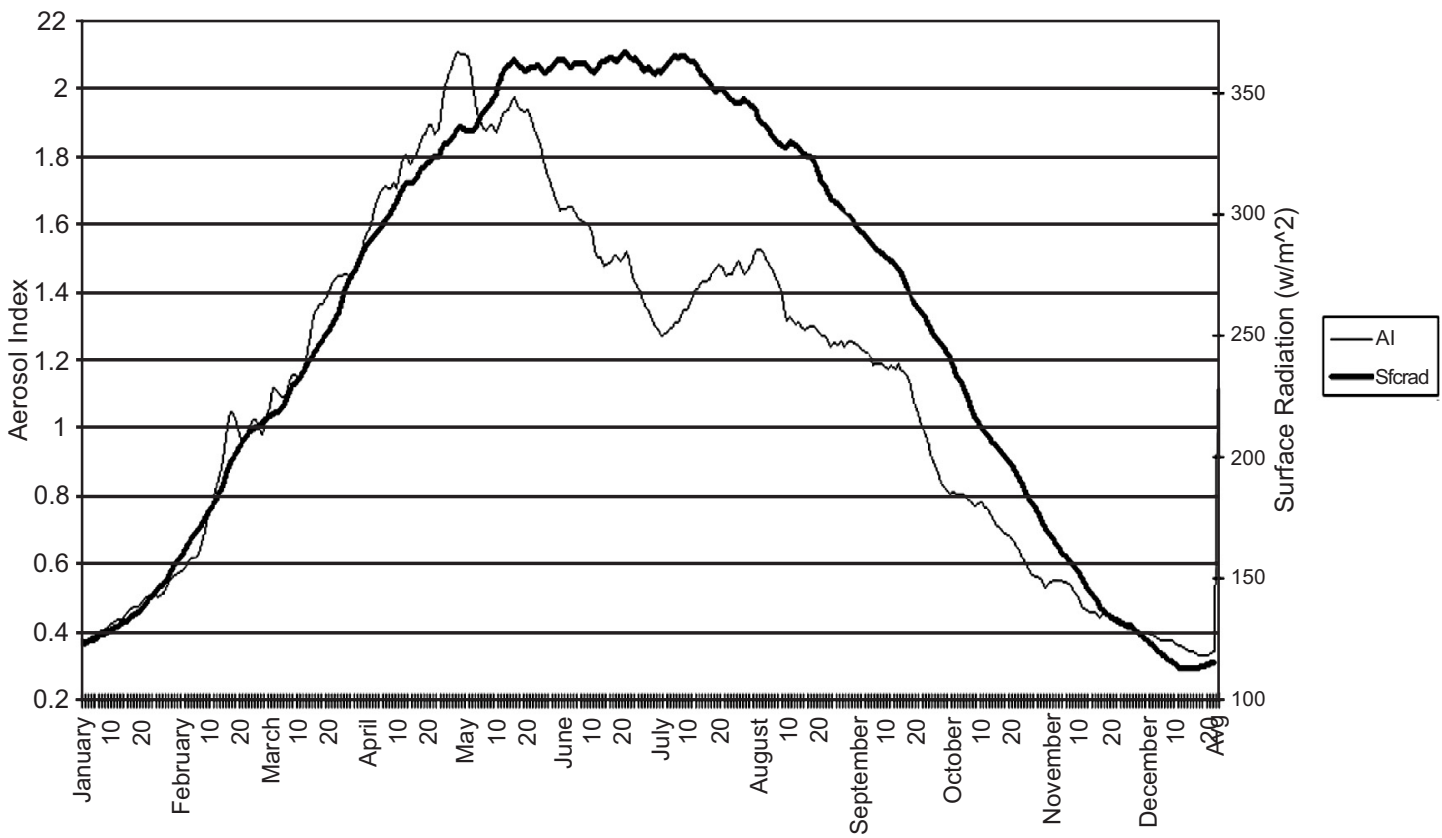


(Fig. 1) contd.....

(e)

Mean Annual Aerosol Index vs. Surface Radiation, 1979-1992.

Atacama Desert: Longitude 71-69W, Latitude 27-18S.

Running Aerage 10 day. Cerrelation Coefficient 0.66.

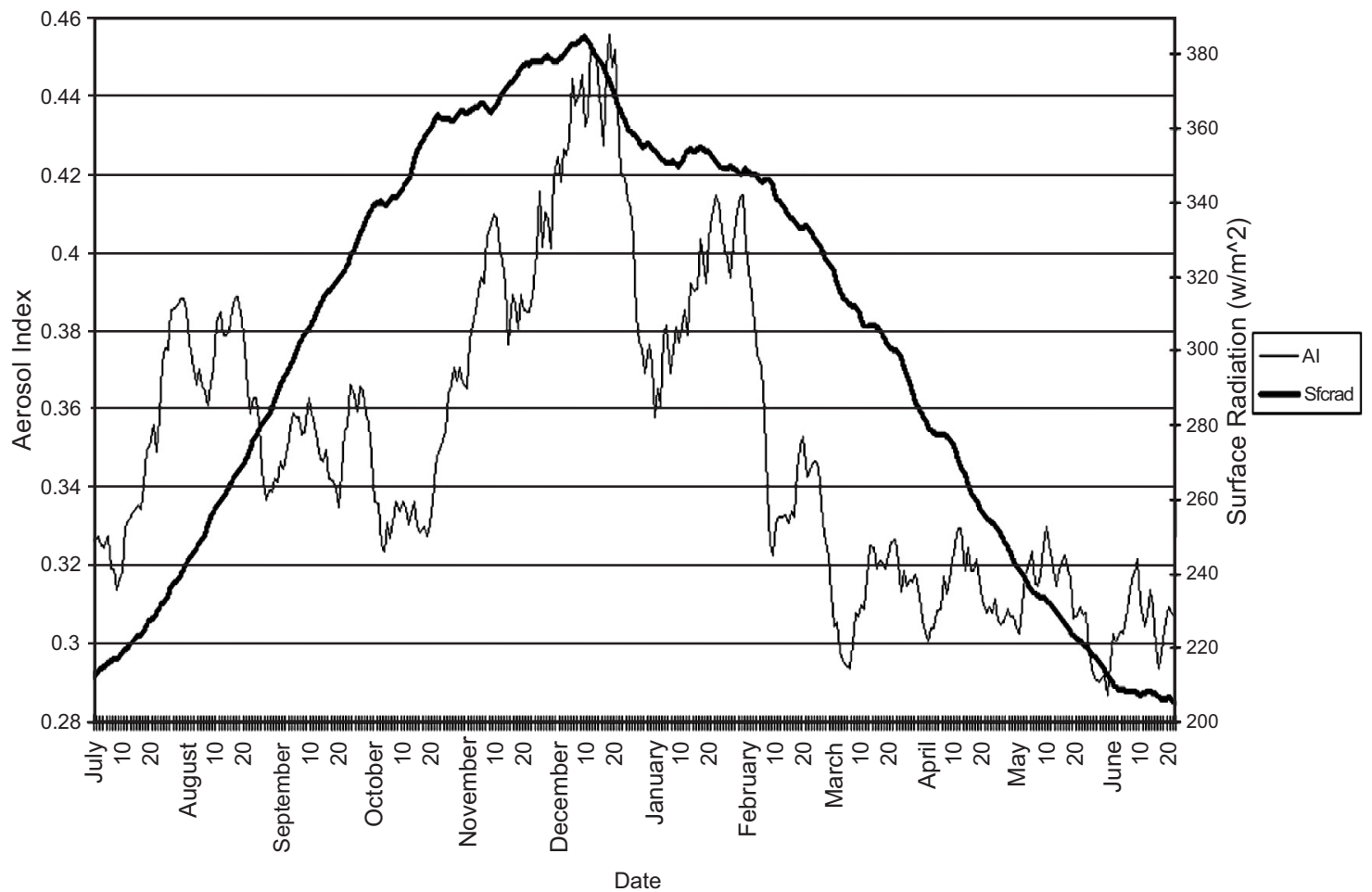

Fig. (1). Annual courses of the solar insolation and the atmospheric dust for five major sandy deserts around the world. (a) The Sahara. (b) The Australian desert. (c). The South Western North American desert. (d) The Taklimakan desert. (e) The Atacama desert. Thin line - AI, thick line - surface radiation.

Table 2. The Annual Relation Between the Aerosol Index and the Surface Radiation for the Major Sandy Deserts of the World. Rows from Left to Right: Name, Aerosol Index Maximum \& Date, Radiation (W/m²) Maximum \& Date, Temperature $\left({ }^{\circ} \mathrm{C}\right)$ Maximum \& Date, Date Difference Rad. Minus AI \& Rad. Minus Temp, Correlation AI-Rad. \& AI-Temp

\begin{tabular}{|c|c|c|c|c|c|c|c|c|c|c|}
\hline Desert & \multicolumn{2}{|c|}{ AI } & \multicolumn{2}{|c|}{ Radiation $\left(W / \mathbf{m}^{2}\right)$} & \multicolumn{2}{|c|}{ Temperature ( ${ }^{\circ} \mathrm{C}$ ) } & \multicolumn{2}{|c|}{ Date Difference } & \multicolumn{2}{|c|}{ Correlation } \\
\hline Australia & 0.6 & $11 / 12$ & 352 & $12 / 20$ & 31.36 & $12 / 30$ & 38 & 10 & 0.75 & 0.44 \\
\hline S.W. USA & 0.57 & $6 / 12$ & 380 & $6 / 15$ & 25.65 & $7 / 7$ & 3 & 23 & 0.96 & 0.66 \\
\hline Atacama & 0.55 & $12 / 8$ & 392 & $12 / 11$ & 16.6 & $1 / 5$ & 3 & 25 & 0.66 & 0.3 \\
\hline Average & & & & & & & 15 & 19.2 & 0.85 & 0.59 \\
\hline
\end{tabular}

explanation is that the increased heating of the deserts in late summer and early autumn causes vertical and horizontal disturbances near the ground, thus affecting chaotically the amount of the dust in the atmosphere.
Fig. (2) is like Fig. (1), but shows the surface temperature instead of the radiation.

In all the deserts, the dust peaks before the radiation peak, albeit the difference is large in the Australian and 
(a)

Mean Annual Aerosol Index vs. Surface Temperature, 1979-1992.

Sahara Desert: Longitude 15E-60E, Latitude 20N-35N.

Running Aerage 10 day. Cerrelation Coefficient 0.86 .

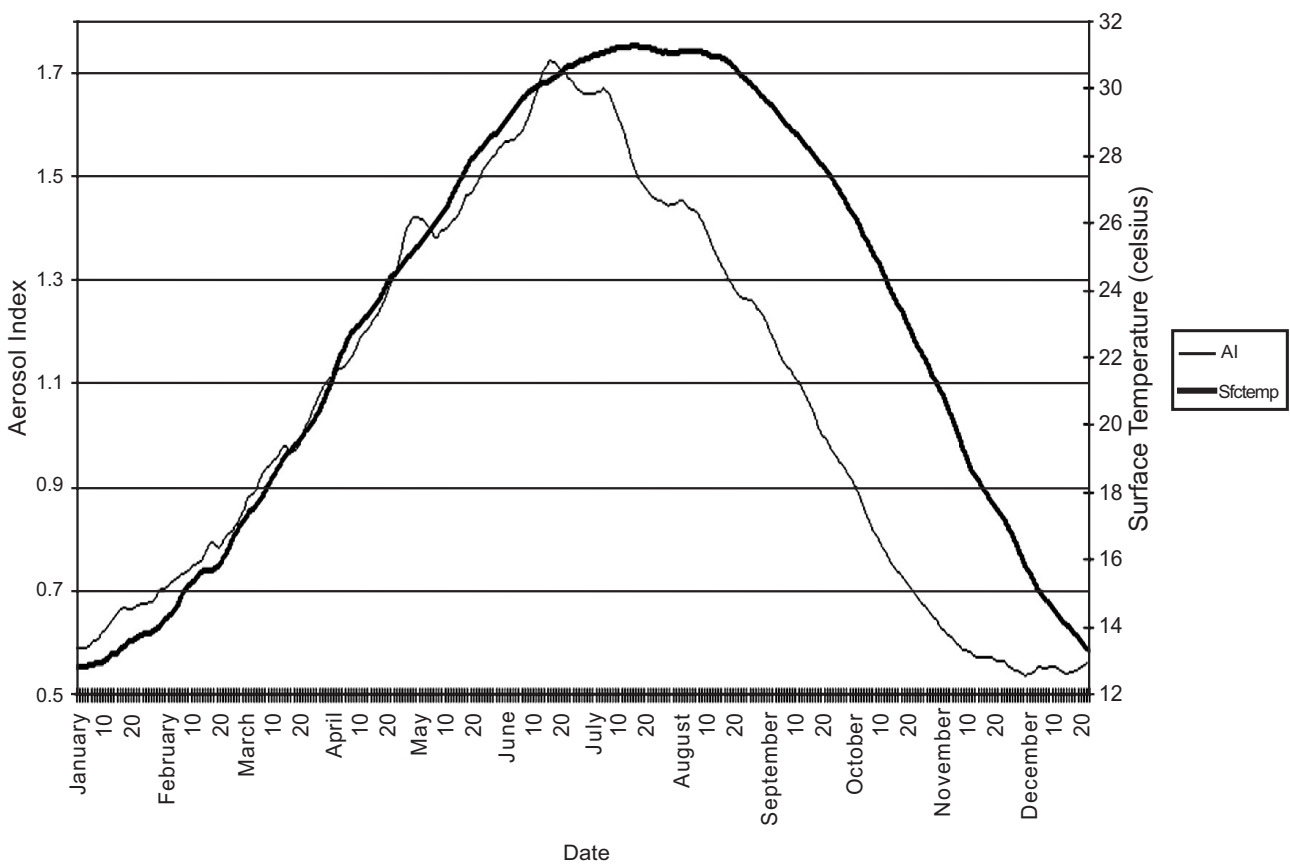

(b)

Mean Annual Surface Radiation vs. Surface Temperature, 1979-1992.

Australian Desert: Longitude 133E-144E, Latituede 31S-13S.

10 days Running Aerage. Cerrelation Coefficient 0.91.

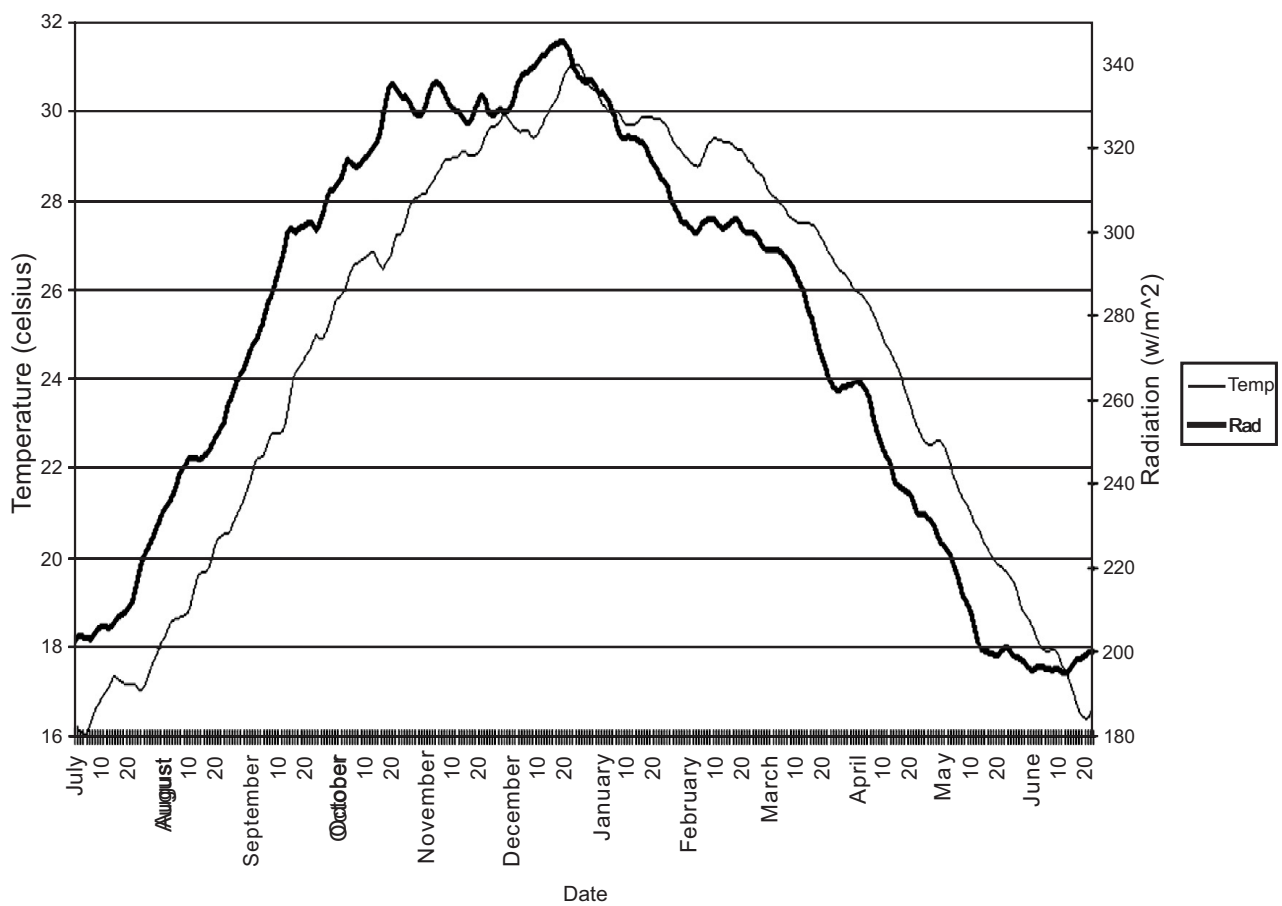


(c)

Mean Annual Aerosol Index vs. Surface Temperature, 1979-1992.

US Southwestern Desert: Longitude 115W-100W, Latitude 30N-40N.

Running Average 10 days. Cerrelation Coefficient 0.66.

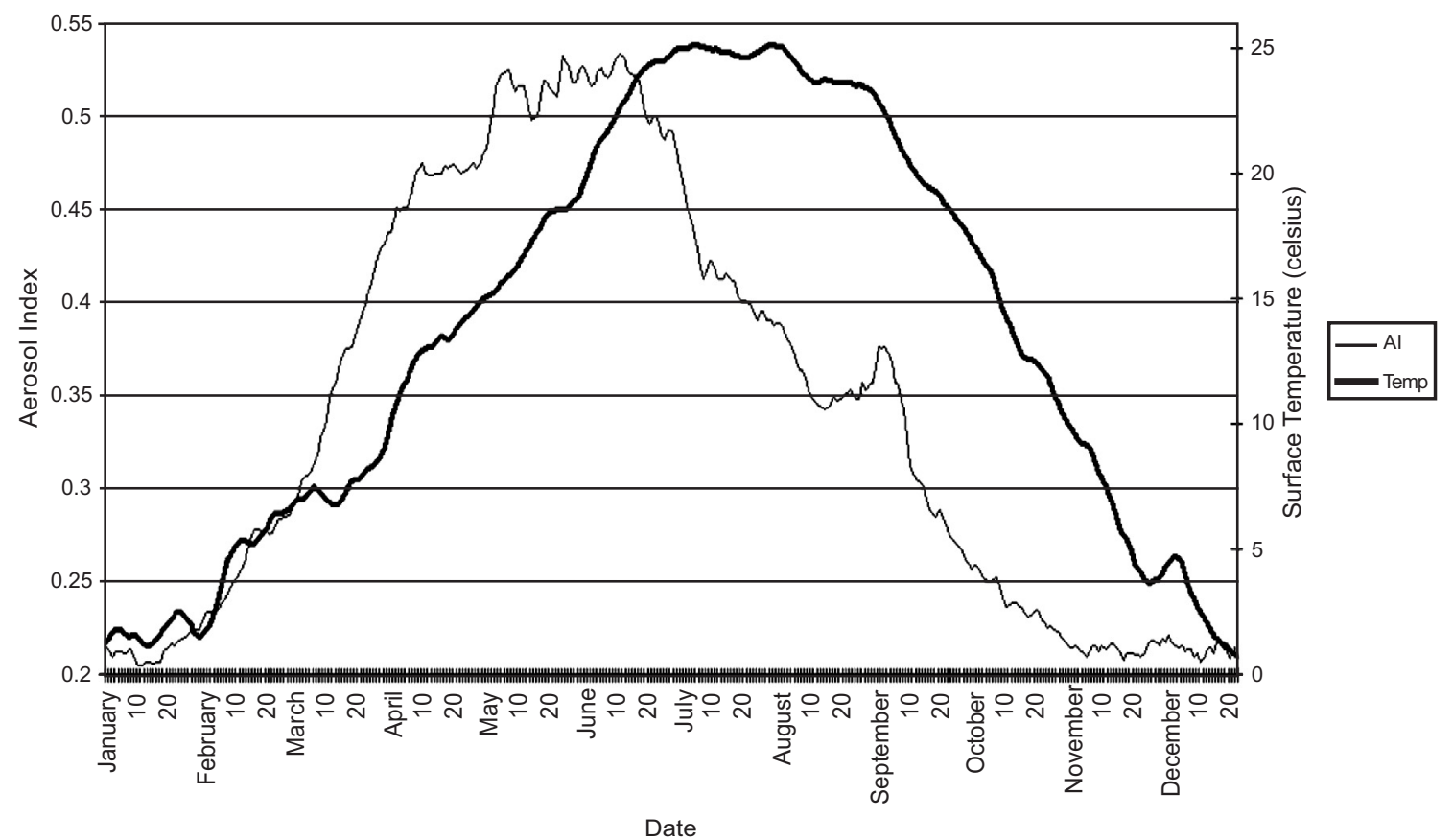

(d)

Mean Annual Aerosol Index vs. Surface Tempreature, 1979-1992.

Taklimakan Desert: Longitude 80E-87E, Latitude 38N-41.5N.

Running Aerage 10 day. Cerrelation Coefficient 0.7.

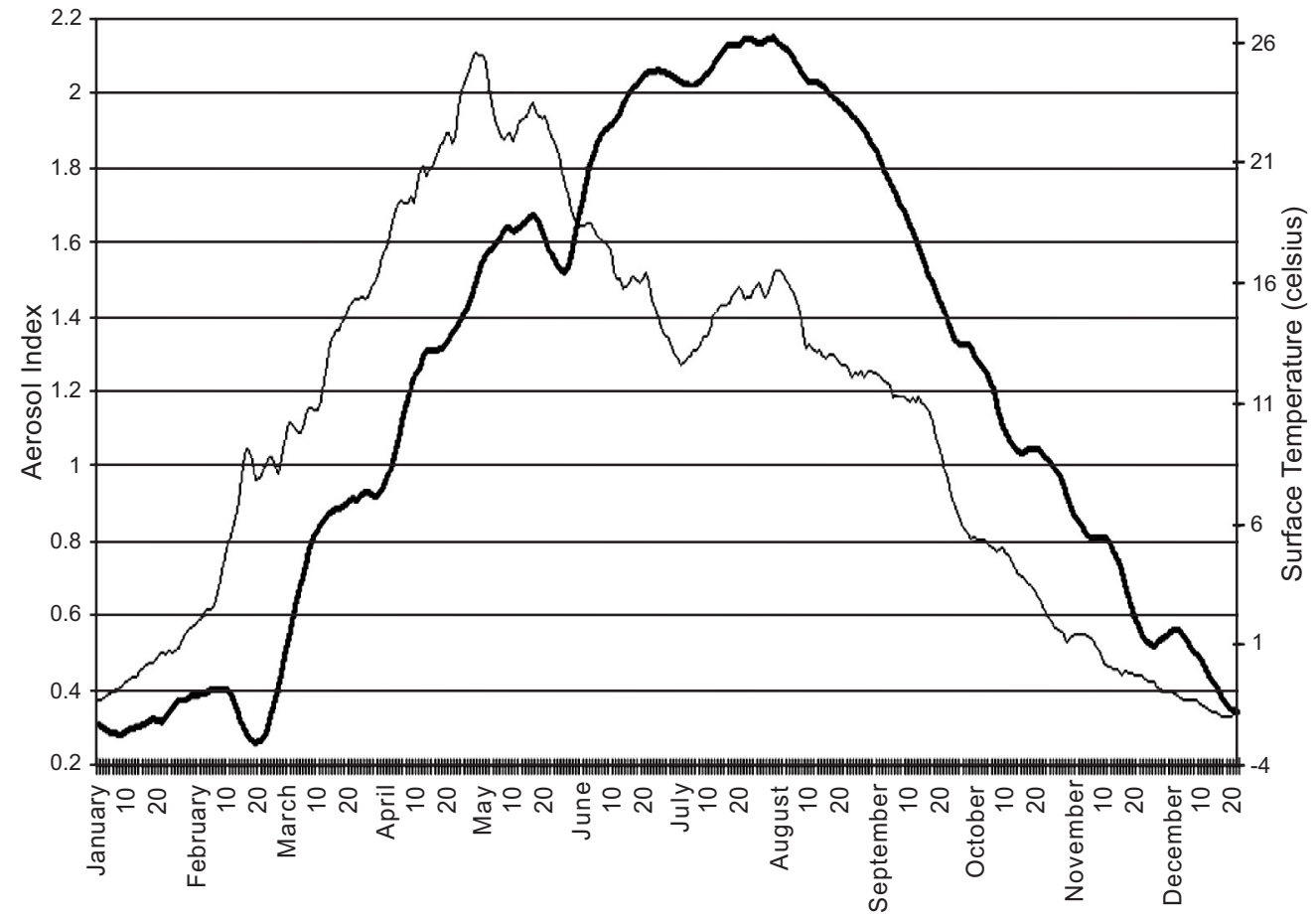


(Fig. 2) contd.....

(e)

Mean Annual Surface Radiation vs. Surface Temperature, 1979-1992.

Atacama Desert: Longitude 71-69W, Latitude 27-18S.

Running Aerage 10 day. Cerrelation Coefficient 0.74 .

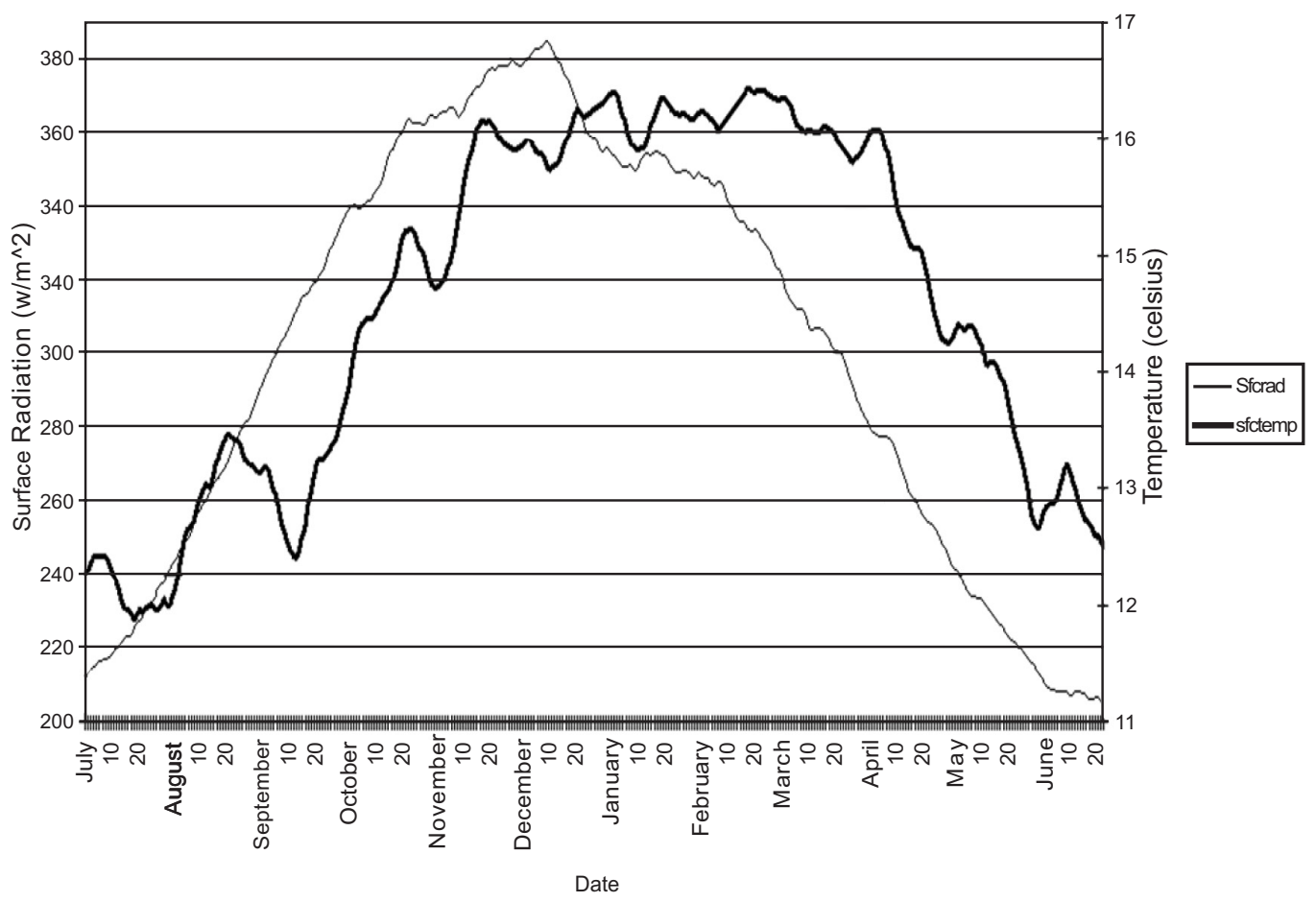

Fig. (2). The same as Fig. (1), but for surface temperature. Thin line - AI, thick line - surface temperature.

Taklimakan deserts, and small in the other three (Fig. 2, Table 2). On the other hand, the temperature always peaks later than the radiation peak (Table 2). The difference between the dust peak and the temperature peak is greater than between the dust peak and the radiation peak.

Of course, the fact that the temperature peak lags the solar insolation peak follows the basic principle of energy budget. Still the fact is that the dust peak is closer to the solar insolation peak than to the temperature peak. Consequently, the forcing of the dust uplift is closely linked to the solar heating and not so to the temperature.

The correlation coefficients between radiation and dust are larger than those between temperature and dust in all of the deserts (Table 2).

The considerably earlier dust peak in the Australian and the Taklimakan deserts is presumably due to differences in topography, climate, and the size of the desert region. The Taklimakan desert is small in comparison with the Sahara, and has a very special topography. It is situated in the Tarim basin, which is a 1,000 meter high plateau, sandwiched between the lofty ranges of the Tien Shan and the Kunlun. This complex topography, along with the fact that the strongest winds causing dust storms occur mainly in spring (Wang et al., 2004) [14], may explain the earlier dust peak. The Australian desert, though larger then the Taklimakan, is still less then quarter of the size of the Sahara. This desert is generally flat, but is blocked to the east by a relatively (to Australia) high mountain range and by higher terrain then the desert itself, to the west. Here, like in the Taklimakan, the spring is the season of the dust storms in the interior of the continent (Ekstrom et al., 2004) [15]. In both of these deserts, the topography, the size difference with respect to the Sahara, and especially the spring dust storms, can explain the deviation of the dust peak date from that of the Sahara.

It is interesting to note the high degree of similarity, between the Sahara, the American, and the Atacama deserts. The latter are considerably smaller then the Sahara. Although they contain dust, the aerosols in them, for the most part, contain other minerals, like salt and mineral deposits. Both deserts are highly mountainous relative to the Sahara. The North American desert is composed of high mountains and plateaus. The Atacama desert is a narrow valley situated between the lofty Andes to the west and the Sierra range to the east (Albritton, 2006) [16]. Their climate is very different from that of the Sahara, so to explain the similarity between them and the Sahara requires further research.

\section{b. The Annual Results}

In order to determine the changes of the $\mathrm{AI}$ and the radiation from year to year, their values and the day of their occurrence are presented in Tables 3 and $\mathbf{4}$. 
Table 3. Peak Value of AI and Surface Radiation $\left(\mathrm{W} / \mathrm{m}^{\wedge}\right.$ 2) by Years

\begin{tabular}{|c|c|c|c|c|c|c|c|c|c|c|}
\hline Year & \multicolumn{2}{|c|}{ Sahara } & \multicolumn{2}{|c|}{ Australia } & \multicolumn{2}{|c|}{ S.W.US } & \multicolumn{2}{|c|}{ Taklimakan } & \multicolumn{2}{|c|}{ Atacama } \\
\hline 1980 & 1.69 & 381 & 0.64 & 380 & 0.8 & 406 & 4.01 & 406 & 1.33 & 402 \\
\hline 1981 & 1.59 & 375 & 0.63 & 387 & 0.66 & 404 & 4.75 & 398 & 1.48 & 410 \\
\hline 1984 & 2.35 & 374 & 0.84 & 363 & 0.84 & 394 & 4.32 & 407 & 1.05 & 416 \\
\hline 1985 & 2.09 & 381 & 0.65 & 395 & 0.65 & 403 & 4.59 & 409 & 0.79 & 392 \\
\hline 1986 & 1.69 & 375 & 0.72 & 403 & 0.6 & 400 & 4.64 & 400 & 1.2 & 408 \\
\hline 1987 & 1.91 & 381 & 0.8 & 384 & 0.68 & 403 & 3.13 & 406 & 1.47 & 424 \\
\hline 1990 & 1.96 & 380 & 0.86 & 380 & 1.06 & 400 & 3.39 & 405 & 0.97 & 404 \\
\hline 1991 & 2.27 & 375 & 1.01 & 395 & 1.02 & 403 & 3.52 & 391 & 1.44 & 419 \\
\hline 1992 & 2.16 & 378 & 1.25 & 407 & 1.03 & 380 & 3.72 & 403 & 0.73 & 420 \\
\hline avg & 1.99 & 377 & 0.84 & 387.5 & 0.8 & 400 & 3.93 & 403.5 & 1.12 & 411 \\
\hline std & 0.26 & 2.9 & 0.2 & 10.8 & 0.16 & 6.7 & 0.6 & 4.9 & 0.24 & 8.4 \\
\hline
\end{tabular}

Table 4. Peak Date of AI and Surface Radiation (Days) by Years

\begin{tabular}{|c|c|c|c|c|c|c|c|c|c|c|}
\hline Year & \multicolumn{2}{|c|}{ Sahara } & \multicolumn{2}{|c|}{ Australia } & \multicolumn{2}{|c|}{ S.W.US } & \multicolumn{2}{|c|}{ Taklimakan } & \multicolumn{2}{|c|}{ Atacama } \\
\hline 1980 & $6 / 21$ & $6 / 18$ & $12 / 27$ & $12 / 31$ & $4 / 17$ & $6 / 16$ & $5 / 16$ & $6 / 9$ & $12 / 22$ & $12 / 1$ \\
\hline 1981 & $7 / 3$ & $6 / 6$ & $11 / 4$ & $12 / 16$ & $6 / 17$ & $6 / 16$ & $5 / 8$ & $6 / 7$ & $12 / 8$ & $12 / 14$ \\
\hline 1984 & $5 / 30$ & $6 / 24$ & $1 / 30$ & $12 / 27$ & $4 / 25$ & $5 / 28$ & $5 / 1$ & $6 / 2$ & $12 / 25$ & $12 / 10$ \\
\hline 1985 & $6 / 22$ & $6 / 9$ & $11 / 30$ & $12 / 13$ & $6 / 2$ & $6 / 28$ & $5 / 26$ & $6 / 14$ & $1 / 17$ & $12 / 27$ \\
\hline 1986 & $6 / 15$ & $7 / 1$ & $12 / 4$ & $12 / 22$ & $6 / 2$ & $6 / 15$ & $5 / 19$ & $6 / 11$ & $12 / 5$ & $12 / 16$ \\
\hline 1987 & $6 / 29$ & $6 / 12$ & $12 / 1$ & $1 / 4$ & $7 / 5$ & $6 / 21$ & $4 / 11$ & $6 / 28$ & $12 / 21$ & $12 / 20$ \\
\hline 1990 & $6 / 18$ & $6 / 8$ & $1 / 16$ & $12 / 25$ & $2 / 20$ & $6 / 3$ & $5 / 17$ & $6 / 24$ & $1 / 7$ & $12 / 10$ \\
\hline 1991 & $5 / 24$ & $6 / 12$ & $12 / 22$ & $12 / 23$ & $6 / 7$ & $6 / 25$ & $5 / 21$ & $6 / 4$ & $12 / 20$ & $12 / 17$ \\
\hline 1992 & $7 / 14$ & $6 / 25$ & $1 / 14$ & $1 / 13$ & $6 / 13$ & $6 / 18$ & $4 / 20$ & $6 / 6$ & $12 / 16$ & $12 / 20$ \\
\hline avg & $6 / 15$ & $6 / 19$ & $12 / 24$ & $12 / 28$ & $5 / 25$ & $6 / 15$ & $5 / 13$ & $6 / 11$ & $12 / 23$ & $12 / 15$ \\
\hline std & 20.4 & 10.1 & 38.6 & 13.8 & 26.4 & 6.8 & 13.8 & 8 & 14.5 & 7.1 \\
\hline
\end{tabular}

Average peak radiation date minus average peak AI date (days): Sahara - 5, Australia - 5, S.W. USA - 22, Taklimakan - 30, Atacama - 9.

Looking at the standard deviation of the annual peak values of the AI (Table 3), one can see that the difference between the years is quite small. For all the deserts, the standard deviation is $10 \%-20 \%$ of the average. For radiation, the annual differences are naturally small; the standard deviation is only $1 \%-2 \%$ of the average, presumably due to local cloudiness.

The peak days of the AI and radiation as presented in Table $\mathbf{4}$ are, naturally, subject in every single year to local 
(a)

Annual Aerosol Index vs. Surface Radiation, 1980

Sahara Desert: Longitude 15E-60E, Latitude 20N-35N Cerrelation Coefficient 0.94

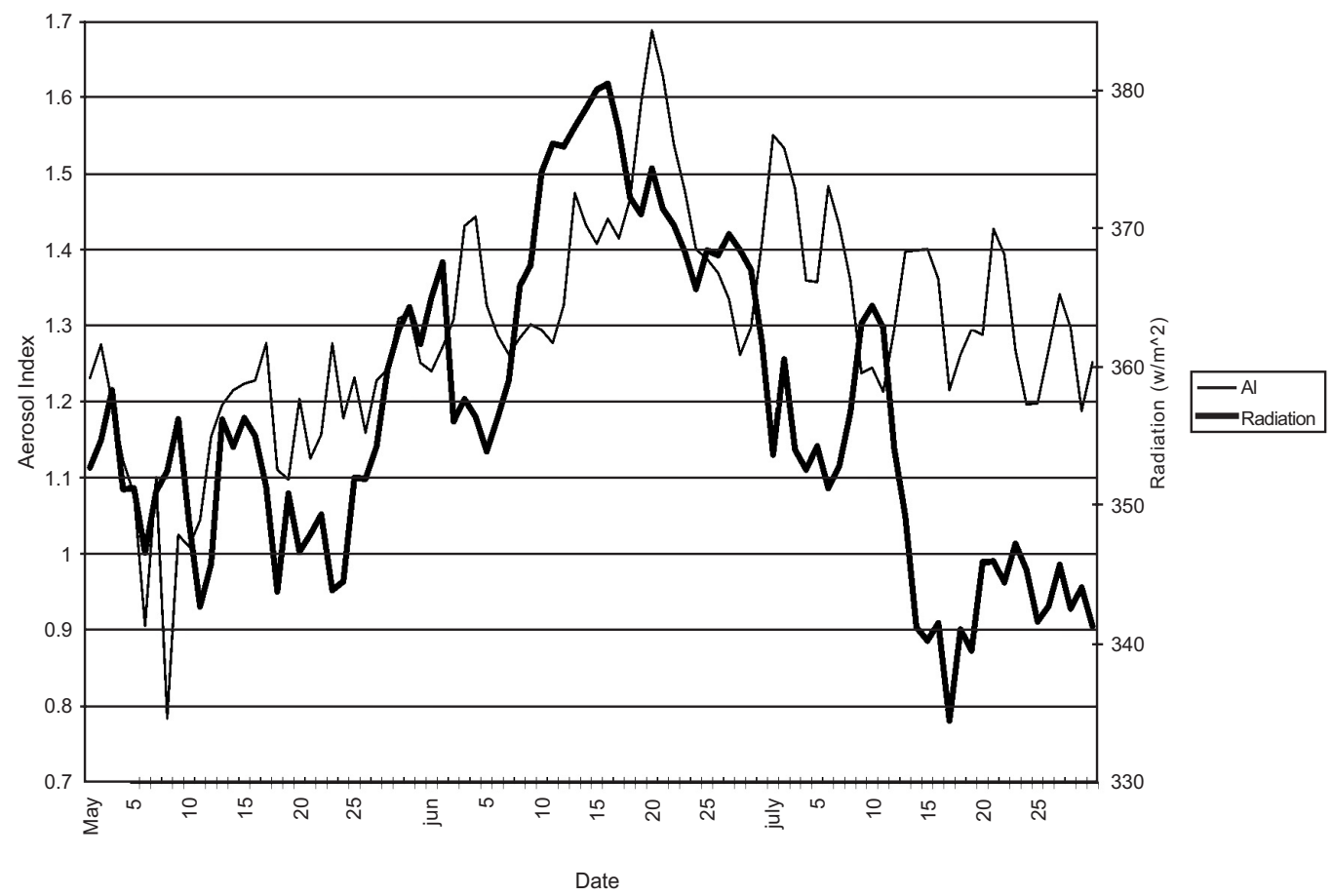

(b)

Annual Aerosol Index vs. Surface Radiation, 1980.

Australian Desert: Longitude 133E-144E, Latitude 31S-13S Cerrelation Coefficient 0.6.

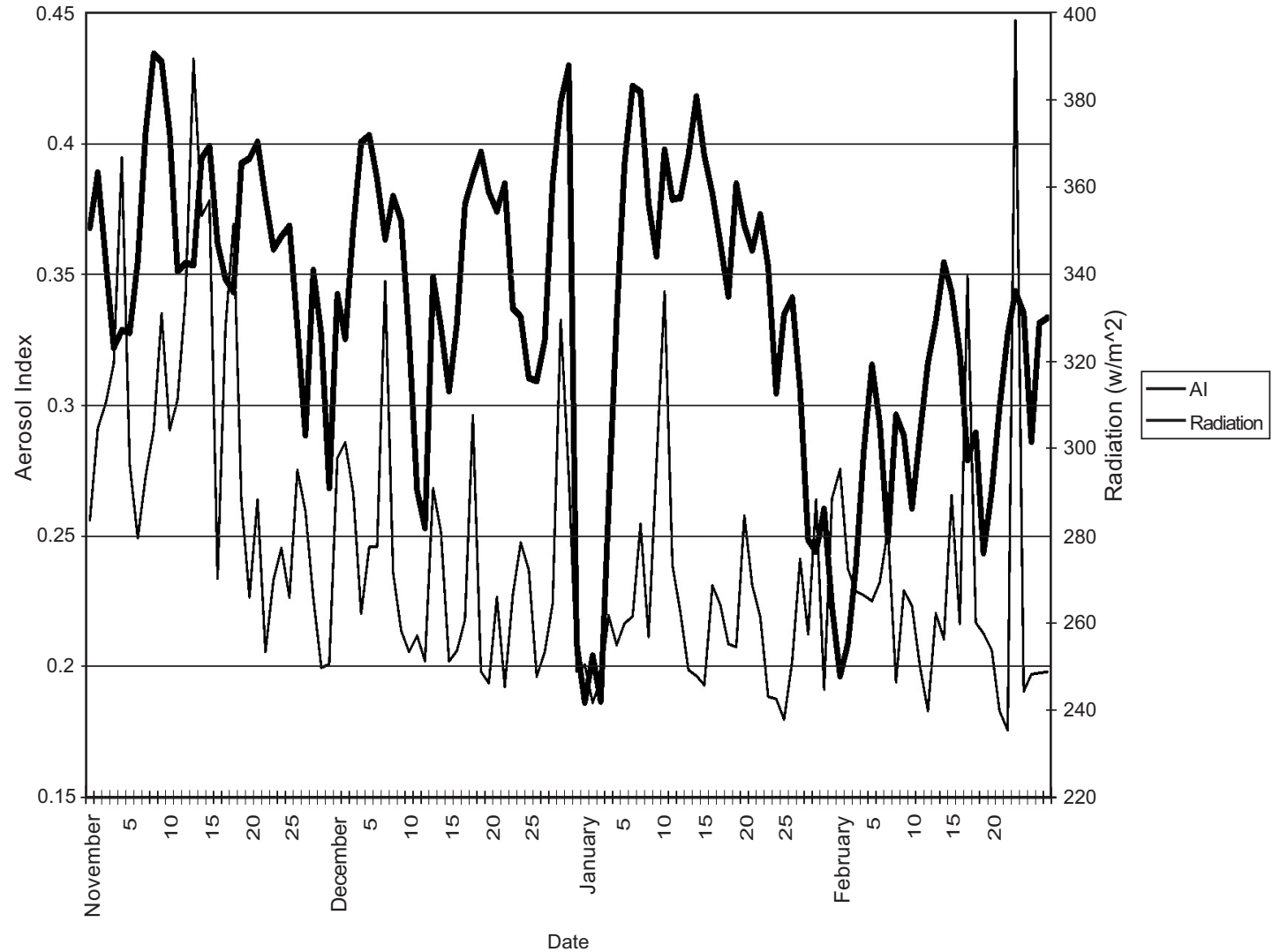


(c)

Annual Aerosol Index vs. Surface Radiation, 1980.

US South Western Desert: Longitude 115W-100W, Latitude 30N-40N Cerrelation Coefficient 0.85 .

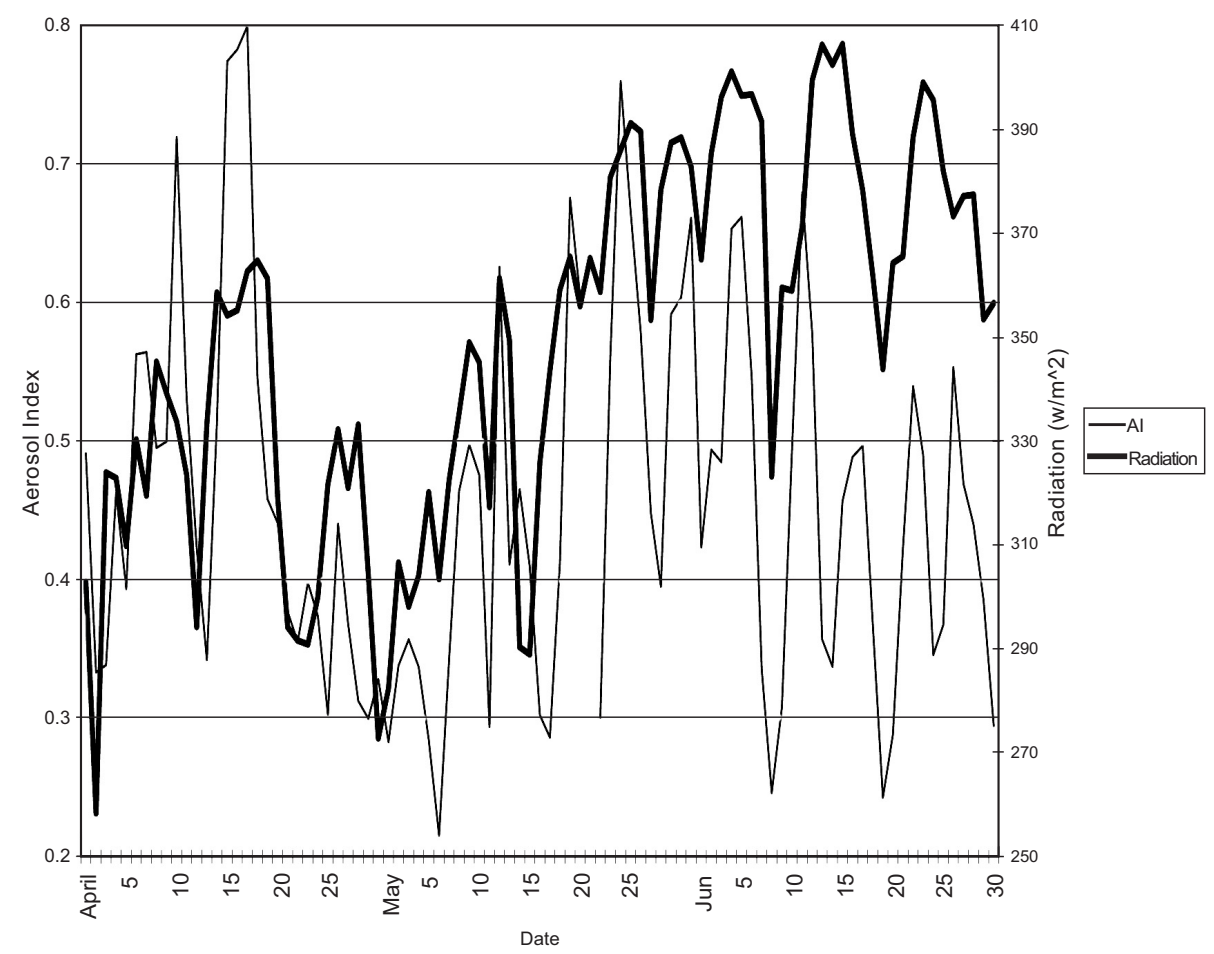

(d)

Annual Aerosol Index vs. Surface Radiation, 1980. Taklimakan Desert: Longitude 80E-87E, Latitude 30N-41.5N. Cerrelation Coefficient 0.87 .

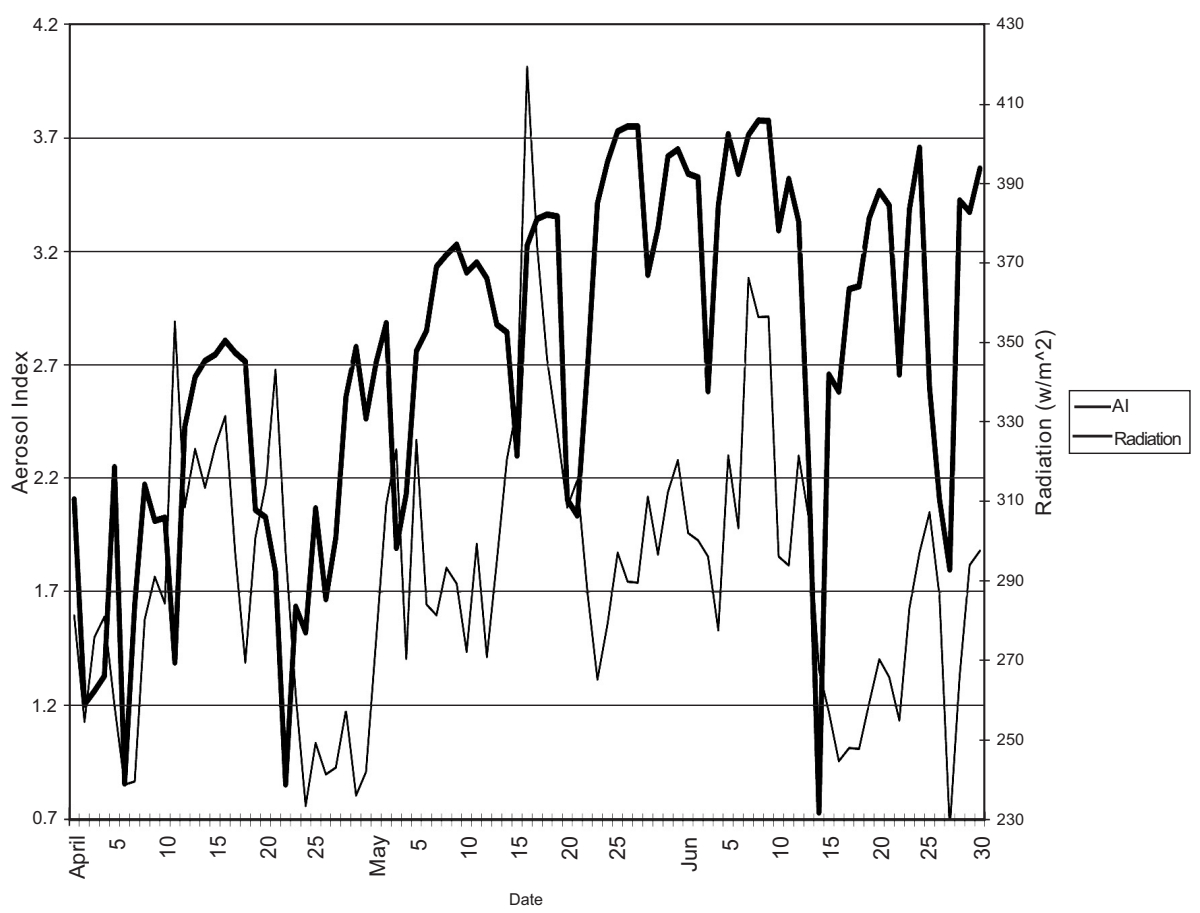


(Fig. 3) contd.....

(e)

Annual Aerosol Index vs. Surface Radiation, 1980.

Atacama Desert: Longitude 71W-69W, Latitude 27S-18S. Correlation Coefficient 0.59.

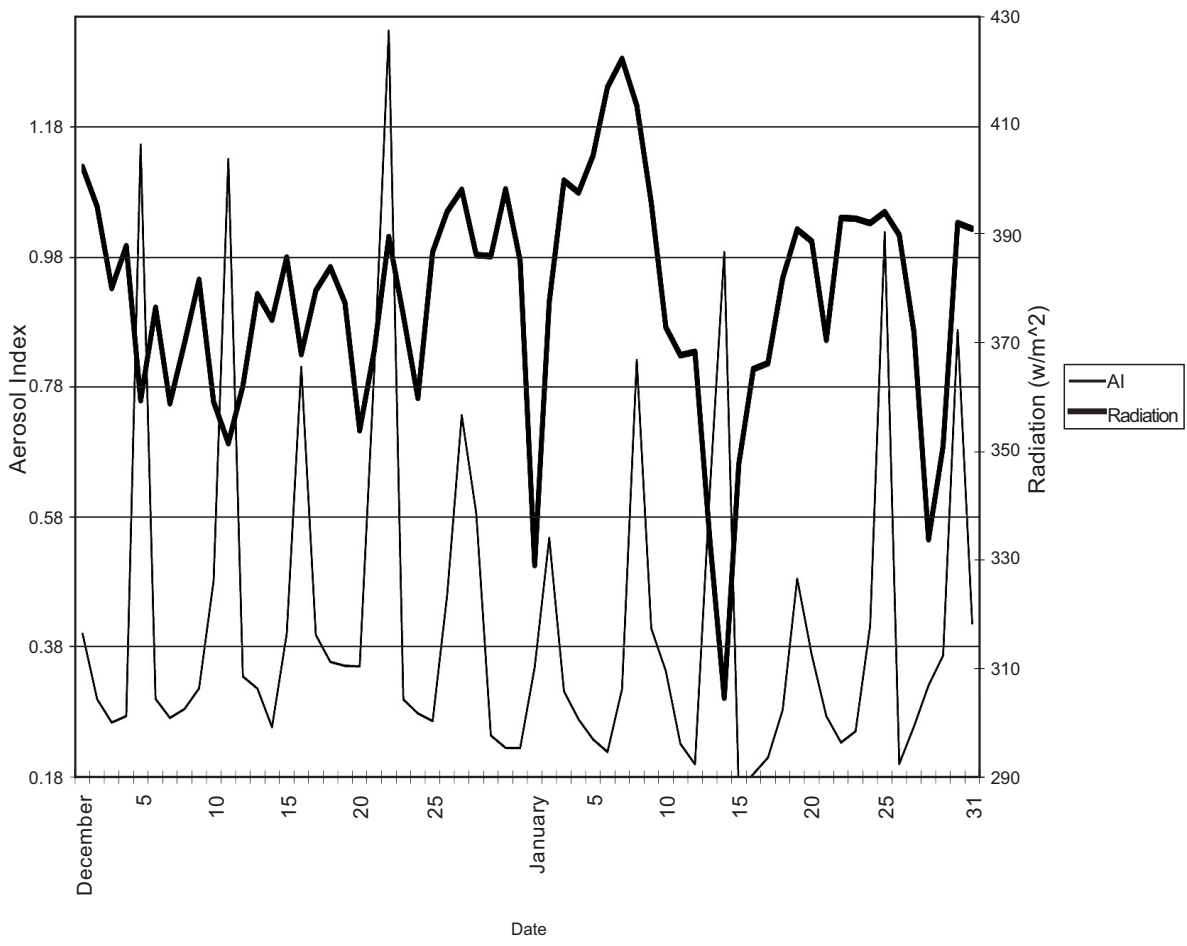

Fig. (3). Courses of the solar insolation and the atmospheric dust load in their peak season, for the year 1980. Thin line - AI, thick line surface radiation. (a) The Sahara. (b) The Australian desert. (c) The South Western North American desert. (d) The Taklimakan desert. (e) The Atacama desert.

phenomena like cloudiness, dust storms, etc. Considering that the theoretical radiation peak in the northern hemisphere is on June 21, and in the southern hemisphere on December 21 , the annual peak days are not very far from these. The radiation peak occurs in all the deserts in June or December, according to the hemisphere. The AI peak occurs in May in the Taklimakan and the US deserts, but closer to the radiation peak in the others. The standard deviations between the years are 7-14 days for radiation and 14-39 days for the AI. The highest standard deviations are in the Australian and US deserts, and the lowest are the Taklimakan and Atacama deserts, meaning that in the two former deserts there are big changes from year to year, while in the two others the changes are smaller. At the bottom of the table, we show the difference in days between the radiation peak and the AI peak. The difference is small, only 5-9 days in the Sahara, Australia, and the Atacama, and bigger in the US and the Taklimakan deserts.

Notwithstanding, one has to take into consideration that in these tables we deal with single peaks. In Fig. (3), we show the daily course of the AI and the radiation for the five deserts in the year 1980 that was chosen arbitrarily. It can be seen that several peaks exist for all the deserts, most of them quite as high as the highest. In spite of this, the correlations remain high, albeit lower than in the smoothed cases. Only a smoothing process through averaging was done in this work, and the discussion of Chapter $4 \mathrm{a}$ can give a generalized view and serves as basis for further research.

\section{CONCLUSIONS}

Comparison between the correlations of the annual courses of solar insolation as well as the atmospheric dust and the surface temperature was performed for the Sahara and other four dusty deserts around the globe, on the basis of 14 years of daily measurements. The other four deserts differ greatly from the Sahara, and one from the other as to their climate, topography, and distance from the nearest great body of water. Three of the deserts are in the northern hemisphere and the other two are in the southern hemisphere.

In spite of these significant differences, the annual link between the solar insolation and the atmospheric dust is similar for all deserts. In the Sahara, North American and Atacama deserts, the difference between the solar insolation peak and the dust peak dates is very small, and is of about 1 to 4 days only. In the Australian and Taklimakan deserts, the dust peak occurs in the spring, earlier then the radiation peak, presumably due to the seasonal dust storms. But the correlation between insolation and dust is high for all the deserts, including the Taklimakan and Australian deserts 
with their early dust peaks (Fig. 1, Table 2). The peak temperature, for all deserts, occurs significantly $(\approx 1$ month) later then the dust peak, and much later in the Australian and Taklimakan deserts. The correlations between temperature and dust are consistently lower than between solar insolation and dust for all the deserts (Fig. 2, Table 2).

Additionally, we computed the same links for the radiation at the top of the atmosphere and for each year separately. There is no significant difference between the top of the atmosphere and the surface radiation.

Concerning the separate years, there are naturally some years with severe dust storms in other seasons, widely separated from the radiation peak date. The radiation peak does not always occur on the exact date of the solstice, due to the local synoptic activity. But generally, the average annual course of the insolation and the dust load are alike. The correlation between them in most of the years is high, between 0.6 and 0.98 , even in years with dust peaks in other seasons.

The final conclusion from this work is that the radiation is the major link with the uplifting and maintaining of the dust in the atmosphere in all the dusty deserts, notwithstanding the differences between them, supporting our earlier conclusion about the strong link between insolation and dust in the Sahara (Alpert et al., 2006) [1].

To further establish the link between dust load and solar radiation, more research needed in topics like synoptics, the influence of topography on the horizontal and vertical wind components, the dynamics of dust behavior in the atmosphere and near the ground, etc. will be mandatory to employ appropriate models in these researches.

\section{REFERENCES}

[1] Alpert P, Barkan J, Kishcha P. A potential climatic index for total Saharan dust: the Sun insolation. J Geophy Res 2006; 111: D01103.
[2] Bagnold RA. The physics of blown sand and desert dunes. New York: Methuen 1965; p. 265.

[3] Balkanski YM, Schulz B, Marticorena G, et al. The impact of the desert dust across the Mediterranean. Guerzoni S, Chester P, Eds. New York: Springer 1996; pp. 69-76.

[4] Stull RB. Introduction to boundary layer meteorology. New York: Springer 1988; p. 666

[5] Herman JB, Bahartia PK, Torres O, Hsu C, Seffor C, Celarier E. Global distribution of UV-absorbing aerosols from NIMBUS/TOMS data. J Geophy Res 102, D14, 1997.

[6] Prospero JM, Ginoux P, Torres O, Nicholson S, Gill E. Environmental characterization of global sources of atmospheric soil dust, identified with the NIMBUS-7 Total Ozone Mapping Spectrometer (TOMS) absorbing aerosol product. Rev Geophys 2002; 40: 2-31.

[7] Kalnay E, Kanamitsu M, Kistler R, et al. The NCEP/NCAR Reanalysis Project. Bull. Am Met Soc 1996; 77(3): 437-71.

[8] Deserts in Australia, Australian Government - Department of Environment and Heritage, 2006.

[9] Barkan J, Kutiel H, Alpert P. Climatology of dust sources in North Africa and the Arabian Peninsula based on TOMS data. Indoor Built Environ 2004; 13(6): 407-19.

[10] Washington R, Martin T, Middleton NJ, Goudie AS. Dust storm source areas determined by the total Ozone mapping spectrometer and surface observations. Ann Ass American Geogr 2003; 93(2): 297-313.

[11] Huang J, Fu Q, Su J, et al. Taklimakan dust aerosol radiative heating derived from CALIPSO observations using $\mathrm{f}$ the Fu-Lion radiation model with CERES constrains; Atmos Chem Phys 2009; 9: 4011-21.

[12] Mason JA, Lu H, Zhou Y, et al. Dune mobility and aridity at the desert region of northern China at a time of peak monsoon strength. Geology 2009; 37(10): 947-50.

[13] Sinha P, Hobbs PV, Yokelson RJ, Blake DR, Gao S, Kirchstetter TW. Distribution of trace gases and aerosols during the dry biomass burning season in southern Africa. J Geophy Res 2003; 108: d17.

[14] Wang X, Dong Z, Zang J, Liu L. Modern dust storms in China: an overview. J Arid Environ 2004; 58 (4): 559-74.

[15] Ekstrom M, McTanish GH, Chapell A. Australian dust storms: temporal trends anrelationships with synoptic pressure distributions (1960-99). Int J Climatol 2004; 24(12): 1581-99.

[16] Albritton R. The Atacama Desert: A physiographic dissection of the hyper-arid desert region of Chile. Geog 330 Cultural Geography, University of Maryland 2006. 